\title{
Entrevista
}

\section{Úrsula Heinze. Viaxe ao real}

\author{
Lidia TeIXEIRo
}

Despois de confirmar que aceptaría a entrevista e que se sente animada para facela, Úrsula Heinze recíbeme cun sorriso tan caloroso que me estremece. Preséntome con flores. Intúo pola súa escrita que lle agradarán, así como a cor escollida, o amarelo. Cargada de profundo simbolismo na súa obra, foi tamén a escollida para a cuberta do seu derradeiro libro, E os domingos, un croissant (Alvarellos Editora). Con este, suman case setenta títulos, nunha traxectoria chea de propostas innovadoras, especialmente na narrativa. Xa está traballando noutra peza, agora un pouco parada por motivos de saúde. Ela di que está cansa pero eu míroa con admiración e case envexa. Diante de min unha muller que me leva na conversa con asombrosa facilidade. Ensíname o real, nun lugar onde «todo custa e se loita por sobrevivir».

-L.T.: Supoño que é a pregunta obrigada pero, quen é Úrsula Heinze? Unha escritora ou moitas escritoras nunha soa muller?

-U.H.: [Responde con moita humildade, rindo] Unha muller que caeu aquí, na Galicia, por casamento. Eu era profesora, pero a miña ilusión de toda a vida era escribir. Cando vin non sabía nin galego nin castelán. En canto puiden agarreime á escritura pero claro, ao principio con moitísimos erros. Iso agradecereillo sempre a Ramón, quen collía os textos e me corrixía. Eu escribía como escoitaba e el dicía: «pero ti que oes?». Escribía como en

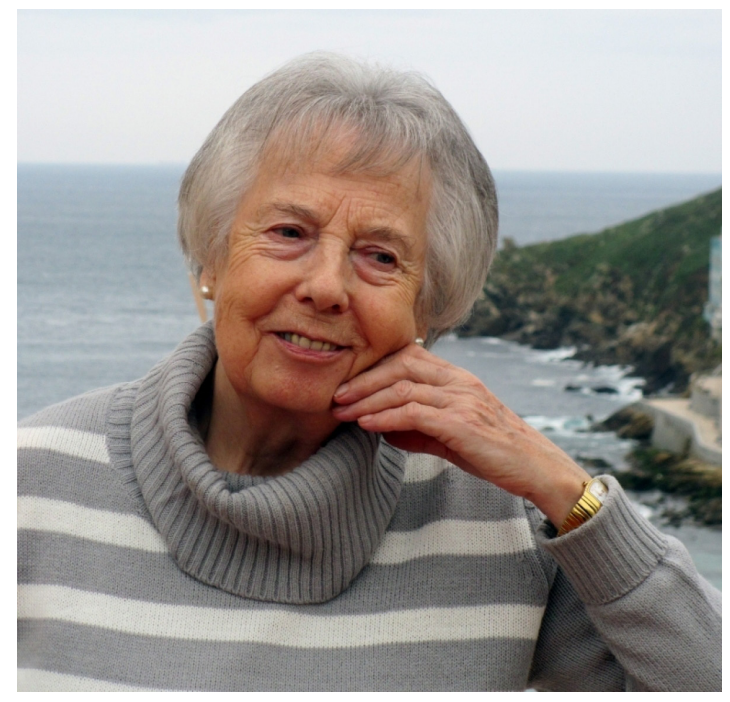

(fotografía: C Alvarellos Editora)

portugués, $a o$, que daquela non estaba permitido e había que modificar moito.

Empecei ao nacer a nosa nena. Eu sempre lle lía cousas en alemán e ela dicía: «por que non me les nada en galego, mamá?». O galego entrou como obrigatorio nas escolas e como aquí non había literatura infatil, a editorial Xerais pediume un libro de literatura infantil.

Eu non son escritora de literatura infantil, aínda que me queren enfiar cara aí. Non me considero como tal. Fíxeno e tivo éxito, máis éxito que todo o demais. Só fixen cinco ou seis libros infantís e o resto son de narrativa e de poesía. 


\section{—L.T.: E algúns moi singulares, ademais.}

-U.H.: Exacto. Fixen varios infantís e despois xa dixen «e isto tamén!». Realmente aí foi cando empecei a escribir para adultos. Sempre tentei facer cousas novas, Xente coma min, cun drogadito, Quérote, unha historia de amor entre adolescentes... Aquí as cousas novas non caían moi ben e, entón, ás veces nin se presentaban os libros. Cando tes unha mala crítica tes que aceptala. En canto publicas algo e o presentas a un público tes que contar con que se non gusta poden dicilo, teñen que dicilo. O peor é cando te silencian, cando non hai nin unha soa crítica. Ao longo dos anos pasoume con moitos libros, desespereime moitas veces porque me pareceu moi inxusto, chámaronme de todo. Foi o momento en que pensei en seguir ou deixalo. Aguantei isto aquí polo de fóra. Entre viaxe e viaxe dos congresos do PEN preparaba conferencias... iso era realmente a miña vida. Os problemas comezaron hai tres, catro, xa cinco anos. Por culpa das cervicais non podía viaxar porque me mareaba moito. Nas últimas dúas viaxes, unha en que volvía de Salvador da Bahía e outra en que volvía de Alemaña, xa no avión me atopei mal. Normalmente ía soa e angustiábame e, nunha viaxe en autobús a Asturias, xa me desmaiei e xa foi o final: «non o podo facer máis».

\section{-L.T.: Había unha Úrsula escritora an- tes de chegar Galicia?}

-U.H.: A pequena escala si. No instituto xa escribía contos, mesmo fun capaz de publicar algún que outro nun xornal diario que tiña os sábados un suplemento, de teatro, literatura...

\section{-L.T.: Cal é o primeiro recordo galego que ten?}

O primeiro recordo galego foi cando coñecín a Ramón e me dixo que era de Santiago de Compostela. Foi no 62. Non dixen nada, «Ai, que ben», e despois na casa collín o mapa «a ver onde está iso». Esa foi a primeira noción de que había un sitio que se chamaba Galicia. E de que había unha lingua, nin idea; nós falabamos alemán. Cando cheguei aquí, no 68, Ramón dixome: «agora tes que aprender galego». Foi moi raro porque me parecía outro home, outra persoa!

\section{-L.T.: Foi un bo profesor?}

-U.H.: El corrixíame pero polo demais eu aprendía a través da escritura, dos libros. Ramón sempre foi un bo compañeiro, moi tolerante. Nunca me reprochou nin me reprocha nada, ao contrario. Agora, a partir de certa idade, nótase o que vale unha persoa. Deixábame viaxar pola miña conta cando iso non era o normal. De feito, dicían: «pero como deixas a Úrsula soa?». Foi tamén moi xeneroso cando eu invitaba a escritores á casa, tivo moita paciencia. El vivira seis anos na Alemaña e sabía as diferenzas. Eu viñera para un sitio en certa maneira sen vida, onde non podías ir a ningún lado. Nas reunións as mulleres e os homes estaban separados. Eu quería estar cos homes pero tiña que estar coas señoras. E de que falaban aquelas mulleres? Dos nenos, de receitas; e para min aquel mundo non existía.

-L.T.: Nunha entrevista realizada por Ana Acuña, vostede sinalaba que mentres Colonia tiña máis de $\mathbf{5 0}$ teatros na altura en que vostede a deixou, Santiago non ofrecía apenas oferta cultural. Sendo observadora privilexiada, como escritora e responsable do PEN club moitos anos, co paso do tempo diría que mellorou a situación? O sistema cultural enriqueceuse ou segue estando por debaixo do que podería ofrecer?

-U.H.: Mellorou moitísimo, penso que mesmo mellorou de máis. Santiago non ten tanta poboación preparada para aguantar un Gaiás. E non teño nada contra el, pero agora hai espazos e a xente non vai. E como non reciben subvencións teñen que pechar.

\section{—L.T.: Que é o que estamos facendo mal?}

-U.H.: Hai que empezar nas escolas. A nós [refírese á Alemaña] en nove anos de instituto, dannos entradas gratis para concertos, para teatros, para que vaias. Ou sexa que xa de nena, desde os dez anos, vas. Son cousas pola tarde, días da semana que non fan funcións de noite. Eu vin teatro e teatro, ópera e ópera, concertos... E, en música [refírese á materia], cando hai oferta de espectáculos, antes, na clase falas desa obra. Xa vas bastante preparado. Coido que é un problema de formación.

-L.T.: E mais agora que temos este problema coas humanidades, non? 
-U.H.: Que parece que non valen! Agora todo é técnica. A danza, a música, como de adulta vas saber se nunca...? Hai que aprender a querelo e a amalo, de neno, de pequeno. Se despois non tes nada que ver, como se non che gusta. Pero sempre hai rapaces que seguen.

-L.T.: Vostede intentou darlle xunto con Ramón ese amor pola música á súa filla Maya?

-U.H.: Si, ela toca o piano, gústalle moito a música clásica. E ela agora co seu fillo, que vai a guitarra. Sen música non vivimos. $E$ hai que dicir que Ramón tamén é un gran amante dela e sempre di que lle doeu moito non ter aprendido a tocar un instrumento.

-L.T.: Un referente literario para vostede.

-U.H.: Heinrich Böll, de Colonia, premio Nobel; sempre admirei a este escritor. Escribiu relatos sobre o que sufriu a xente despois da guerra, dunha forma moi sinxela, accesíbel, que todo o mundo entendía. Usaba as palabras que usa a xente.

\section{—L.T.: E galego?}

-U.H.: Na escritura, Martínez Oca. Sempre me gustou moito.

-L.T.: Os seus textos descatan por teren unha escrita moi fluída, onde a complexidade reside no seu simbolismo.

-U.H.: Hai moito detrás. E teño até poemas musicalizados, en alemán, cantados por unha soprano. Sempre me dicían que teño moita musicalidade. Unha editora que tiña en Berlín dixo que ía buscar un compositor que os musicase e conseguímolo. Fíxose unha presentación e foi unha cantante moi nova, de ópera; fíxoo moi ben. Desgrazadamente, isto grabouse pero nunca conseguín a grabación. Supoño que a editora quedou con ela.

-L.T.: O alemán é unha lingua á que regresou literariamente, non?

-U.H.: Si si, iso foi un punto tamén de ruptura. A min déronme en Croacia un premio por unha tradución de literatura eslava, que debía consistir en cartos e nunha estadía entre 1 e 6 meses nese país. Os cartos voaron porque non podían darme case nada, e quedei durante un mes nunha illa con todo pago en Hvar. O dono do pazo onde eu quedei, máis ou menos da miña idade, sabía alemán. Pedíronme no final do mes escribir algo e fíxeno en alemán porque el sabía e podía preguntarlle cousas. Isto publicouse como unha cousa moi sinxela. Empecei outra vez co alemán e a poesía. Os primeiros libros foron bilingües alemán e galego e despois tiven oportunidade de publicar tamén relatos en Suíza, na suíza alemana, das miñas viaxes.

-L.T.: A idea de editar bilingüe responde a unha cuestión editorial, un desexo de reflectir dúas voces dunha mesma muller?

-U.H.: Foi un pouco por Isaac Díaz Pardo. Díxenlle a Ramón: «vou preguntar a Isaac se me publica isto». E dicía Ramón: «pero ti que te cres, que che vai publicar eso bilingüe?». Eu fun e el dicía: «bueno, filliña, ti vente e eu publícoche todo o que fas, sei que o fas ben...». Despois el tivo ese problema coa editorial, con Sargadelos e con todo iso. Eu sempre pensaba: «teño que apurar porque este home morre, morre!», e non morría, non; quitáronlle a fábrica, quitáronlle todo. Pero catro libros aínda fixen alí. Despois, fixen outro bilingüe con FernánVello, Skyline, e outro con Follas Novas.

Tiña medo da poesía. Na poesía deixas voar os pensamentos. Son as palabras exactas que tes que empregar. Para atopar esa palabra, empezo a pensar e pensar e váiseme o pensamento. Tiña medo de non poder controlar as ideas e non quería caer na tristeza e na nostalxia. Dixen: «non, non fago máis diso, non fago máis, porque teño medo de min mesma». Pero despois [referíndose a volver a escribir] pensei: «vouno facer outra vez». Para min foi como unha terapia.

-L.T.: De que traballos se sentiu máis satifeita?

-U.H.: É difícil de dicir. Máis satisfeita, quizais do último ( $E$ os domingos, un croissant). Isto son eu. As novelas son inventos en gran parte, hai un fondo de verdade e o resto é invención; e neste non, isto son eu. Sempre o digo, hai vinte anos nunca escribiría este libro, porque eu aí íspome realmente, e presentalo a un público... Agora dáme igual. 
Todos os días, con data, como está no libro, empecei a escribir. Levávame tres cuartos de hora. Observaba o que pasaba, falaba cos que me contaban algo e así, pouco a pouco, foise enchendo. Cando tiña bastantes páxinas pensei en dicirlle ao mundo o que hai nun psiquiátrico para quitar o mito de todo iso. Para facerlles ver o que hai aquí dentro porque, eu, vivino.

Fun valente. Eu quería publicalo. Isto é o que sinto. Quería que a xente o soubese. O médico dicíame: «non te enganes, aquí o mundo é moi irreal, o mundo real vas telo fóra». E non é certo, eu discutinllo moitas veces. Aquí [no Sanatorio La Robleda] é o mundo real, aquí mostrámonos como somos. Non tes que inventar nada; se non queres unha persoa, non a queres, se a queres, dáslle un bico. Fóra disfrázaste, tes que ser diplomático. Iso discutireino até a fin dos meus días: aquí es como es, fóra non. Porque non te podes permitir ese luxo.

\section{-L.T.: Neste libro hai unha novela ou máis ben un retrato?}

-U.H.: Novela non, eu creo que novela non se pode dicir. É máis ben retrato porque eu non invento nada aí, isto é todo realidade. Claro, tiven que traballar despois o texto, porque eu máis ben apuntara cousas e despois na casa había que repasalas. Mesmo creo que aínda hai unha cousa que repito, que non me dou conta. Nada inventado, iso é o que hai aquí dentro; é a realidade, non teño nada engadido. Todos os nomes que están aquí existen, son de verdade. Eles recoñécense perfectamente. Só o médico e eu, temos nomes reais.

\section{—L.T.: Ten algún traballo sobre a mesa?}

-U.H.: Agora cando me pasou isto [novamente problemas de saúde], estaba corrixindo. A metade xa estaba e a outra metade non. Remateino, hai que darlle voltas. Fíxeno estando xa bastante mal. Eu escribo todo á man e despois pásoo ao ordenador. Como non podía co lumbago cometín moitos erros. Vai tamén do mundo da psiquiatría porque é un pouco agora o meu mundo; pero tamén despois pararei. Non escribo máis, non vou ser unha experta niso. Este libro tíñao xa na cabeza.

-L.T.: Un lugar ao que volvería e outro ao que non regresaría.
-U.H.: Volvería a toda a antiga Iugoslavia. Teño un especial cariño á xente de Eslovenia, a onde fun once veces, convidada. Os eslovenos son un pouco como os austríacos, comparten fronteira e é o país das mil augas. E despois as pradeiras con todo verde, con esas flores típicas das montañas. A xente é moi amábel; o pouco que teñen compárteno contigo. Cando te saúdan traen un plato con sal, pan e con bebida. Esa bebida é tan forte que tes tragar como... [rise]. Despois Croacia, que visitamos mesmo durante a guerra, e na biblioteca de Dubrovnik hai libros meus... Macedonia, onde hai unha serra de montes que se chama Galicia e é un país precioso. A todos estes países volvería.

A onde non volvería? A Moscú creo que non. A pobreza que vimos... Saías dun hotel e á volta vendían de todo: cravos, páxinas de papeis. Do luxo do hotel á pobreza máis grande que te poidas imaxinar, todo gris. A Atenas, tampouco, ves Taller de Sócrates e dis: «será posible?», un taller de coches rotos... non, aí non. Ás illas si, pero á capital non.

\section{-L.T.: Algo que lle tivese gustado facer e que non fixo?}

-U.H.: Non, satisfacción total. Fixen todo o que quería facer, mesmo teño que dicir que moito máis do que nunca pensei. Nunca pensei que sería capaz. Agora non quero máis nada porque todo o que tiña na cabeza leveino a cabo. Tanto escrito como por viaxar.

Fóra recoñecéronme, apreciábame. E eu, eu disfrutaba, organizaba nos congresos, moderaba mesas, axudaba porque sabía idiomas. Eu fisicamente estaba aquí, preparaba os escritos, as cousas, os libros, e despois ía con isto a fóra. Paseino moi ben. Co PEN sempre tiñamos recepcións, cos mandatarios e con altos cargos que nos invitaban as ceas, a comidas. Só estabamos nos mellores hoteis de Brasil, Viena, Madeira. No congreso que organicei en Santiago de Compostela, no ano noventa e tres, estabamos case todos no Hostal dos Reis Católicos. Foi unha vida reamente moi completa. Boteina de menos cando deixei de viaxar; agora xa non. Moitas veces preguntaban: «E que é de Úrsula?». 


\section{-L.T.: A falta de saúde impediullo.}

-U.H.: É que non podía. A forza agora é limitada, eu non aguantaría todo un día de pé, sempre amábel, de conversa. Ademais que tamén a xente cambia, os que foron comigo tampouco xa van porque é todo xente de certa idade.
—L.T.: Un epílogo para a súa produción literaria.

-U.H.: Que a lean, que lles guste e que a entendan! Moitas veces collo un libro e non me di nada. Eu non escribín para que lles guste pero esperei sempre cando escribía que lles gustase o que fago. 